\title{
AMMONIA AS A MODIFIER IN ION MOBILITY SPECTROMETRY: EFFECTS ON ION MOBILITIES AND POTENTIAL AS A SEPARATION TOOL
}

\author{
ROBERTO FERNÁNDEZ-MAESTRE ${ }^{1,1}$, CHING WU², AND HERBERT H. HILL JR. ${ }^{3}$ \\ ${ }^{1}$ Universidad de Cartagena, Campus de Zaragocilla, Programa de Química, Cartagena, Colombia \\ ${ }^{2}$ Excellims Corporation, 20 Main Street, Acton, MA, USA, \\ ${ }^{3}$ Department of Chemistry, Washington State University, Pullman, WA 99163, USA, \\ (Received: July 20, 2012 - Accepted: December 4, 2012)
}

\begin{abstract}
A commercial ammonia solution was introduced in the buffer gas of an ion mobility spectrometer and the mobilities of tetramethylammonium (TMA), tetraethylammonium (TEA), tetrapropylammonium (TPA), and tetrabutylammonium (TBA) ions, tribenzylamine (TBzA), tributylamine (TBtA), 2,4-dimethyl pyridine (2,4-lutidine), 2,6-di-tert-butyl pyridine (DTBP), serine, atenolol, and valinol decreased depending on their structures. Electrospray ionization-ion mobility spectrometry-quadrupole mass spectrometry was used in these experiments. Analyte ion mobilities decreased to different extents with the amount of ammonia introduced in the mobility spectrometer. When the amount of ammonia increased from 0.0 to $22 \mathrm{mmol} \mathrm{m}^{-3}$ (with a concomitant concentration of water of $106 \mathrm{mmol} \mathrm{m}^{-3}$ ), percentage reductions in mobilities were: $-4.8 \%$ (serine), $-1.9 \%$ (reactant ions), $-1.1 \%$ (TBtA), $-0.9 \%$ (TBzA), $-0.5 \%$ (TEA), $-0.4 \%$ (valinol and TBA), $-0.3 \%$ (TEA, TMA, and 2,4-lutidine), and $0 \%$ (atenolol and DTBP). These selective variations in mobilities were due to formation of large analyte ion-ammonia-water clusters. The small change in mobility of tetraalkylammonium ions, TBzA, TBtA, atenolol, and DTBP with the introduction of ammonia into the buffer gas was explained by steric hindrance of bulky substituents which shielded the positive charge of the ion from the attachment of ammonia and water molecules, and delocalized the positive charge. Ammonia in the buffer gas produced ion clusters with one or two ammonia molecules in compounds with little steric hindrance such as serine. At concentrations of ammonia of $4.4 \mathrm{mmol} \mathrm{m}^{-3}$ or higher (at $150^{\circ} \mathrm{C}$ ), ligand-saturation with ammonia and water molecules occurred on the positive charge of some ions; when the positive charge saturated, no significant reductions in ion mobility occurred when increasing the concentration of ammonia in the buffer gas.
\end{abstract}

Keywords: Ion mobility spectrometry, gas modifier, ammonia, clustering, dopant

\section{INTRODUCTION}

IMS is an analytical technique that separates gas-phase ions moving in a drift tube under an applied electric field based on their size to charge ratios. IMS was introduced in 1970 by Karasek as detector for volatile organic molecules, ${ }^{1}$ and it became the analytical technique preferred for the analysis of explosives, ${ }^{2}$ illicit drugs, ${ }^{3-5}$ and chemical warfare degradation products. ${ }^{6-7}$ IMS has been used as a detector for liquid ${ }^{8}$ gas,${ }^{9}$ and supercritical fluid chromatography. ${ }^{10}$ IMS has also been applied to the determination of nicotine in tobacco, ${ }^{11}$ microorganisms,${ }^{12}$ analysis of protein structures ${ }^{13}$ study of the three-dimensional shape of polyatomic ions, ${ }^{14}$ and the separation of isomeric peptides..$^{15}$ IMS has given an additional dimension of analysis to investigations by mass spectrometry; when coupled to mass spectrometry, IMS has been applied to metabolomics, ${ }^{16}$ and proteomics. ${ }^{17}$

When electrospray is used as the ionization source in IMS, the solvent molecules are stripped from the ions in a desolvation region by means of a heated counter-current flow of nitrogen buffer gas. This desolvation process produces single stable gas phase ions which are then pulsed by an ion gate into a drift region. The ions in the drift region are decelerated by repeated collisions against the buffer gas but are simultaneously accelerated by the electric field. This combination of decelerations and accelerations rapidly thermalizes the ions, and averages their velocities to a characteristic value that depends on their collision cross sections. These velocities can be used to calculate mobility constants, $K$, a characteristic parameter of the ions: ${ }^{18}$

$$
K=\frac{v}{E}=\frac{L^{2}}{V \cdot t_{d}}
$$

where $v$ is the velocity of the ion in $\mathrm{cm} \mathrm{s}^{-1}, E$ the electric field in the drift region in $\mathrm{V} \mathrm{cm}^{-1}, L$ the distance in centimeters the ion travels from the ion gate to reach the detector, $V$ the total voltage drop in volts in the drift region, and $t$ the time the ion takes to travel the distance $L$ in seconds. If the electric field is less than $\sim 500 \mathrm{~V} \mathrm{~cm}^{-1}$ (at atmospheric pressure), $\mathrm{v}$ should be a linear function of $E .{ }^{19} \mathrm{To}$ compare values of $K$ in different experimental conditions, ion mobilities must be normalized to standard conditions. This normalization yields reduced mobilities (in $\mathrm{cm}^{2} \mathrm{~V}^{-1} \mathrm{~s}^{-1}$ ) which are characteristic of every compound in a given buffer gas:

$$
K_{0}=K \frac{P}{760} \frac{273}{T}
$$

where $\mathrm{P}$ is the pressure in Torr and $\mathrm{T}$ the temperature of the buffer gas in Kelvin..$^{19}$

Ion mobility spectrometry using buffer gas modifiers separates ions in a gas phase by exposing ions to a polar modifier. ${ }^{20-22}$ These modifiers enhance ion-molecule interaction forces. When polar modifiers are introduced into a buffer gas, they interact with the analytes ions depending on the ion structures and steric hindrance of the atoms bearing the charges; this interaction leads to the formation of clusters of different sizes that spend different times inside the drift tube. These clusters may be used to separate analytes that overlap in IMS. In a recent work, water did not significantly change the ion mobilities of analytes when it was introduced into the buffer gas, ${ }^{21}$ and it was uncertain if it was because of its size; the subject of this investigation was to investigate another low molecular weight modifier, ammonia, to compare the changes in ion mobilities with those of water when they are introduced into the buffer gas and demonstrate that the small changes in mobilities with small modifiers are due to their sizes; also, to determine the capabilities of ammonia in generating selective ion separations.

\section{EXPERIMENTAL SECTION}

Instrument. Experiments were carried out on an ion mobility spectrometer coupled to a quadrupole mass spectrometer through a $40-\mu \mathrm{m}$ pinhole (Figure 1). The IMS instrument used an electrospray ionization source at atmospheric pressure. Routinely used operating conditions for this instrument were: sample flow, $3 \mu 1 \mathrm{~min}^{-1}$; drift tube length, $25.0 \mathrm{~cm}$; ionization region length, $7.5 \mathrm{~cm}$; ESI voltage, $15.6 \mathrm{kV}$; voltage at first ring, $12.1 \mathrm{kV}$; voltage at the gate, 10.80 $\pm 0.01 \mathrm{kV}$; gate closure potential, $\pm 40 \mathrm{~V}$; gate pulse width, $0.1 \mathrm{~ms}$; scan time, $35 \mathrm{~ms}$; averages for every spectrum, 1000; pressure, 680-710 Torr; buffer gas, nitrogen; buffer gas flow, 0.93 liter $\mathrm{min}^{-1}$; buffer gas temperature, $150 \pm 2{ }^{\circ} \mathrm{C}$; ammonia flow rate, 0.17 to $0.75 \mu 1 \mathrm{~min}^{-1}$. 


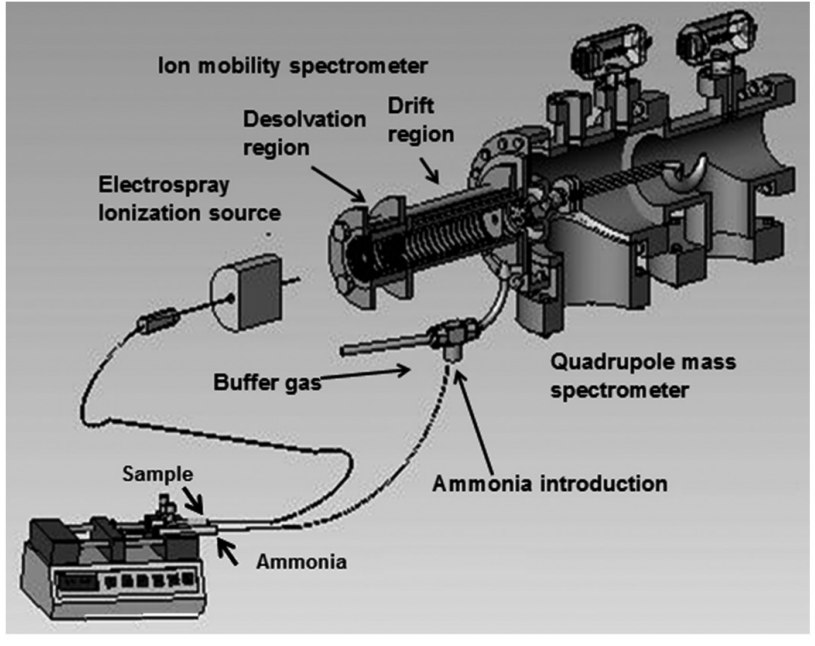

Figure 1. Diagram of the electrospray ionization-atmospheric pressure ion mobility-quadrupole mass spectrometer.

IMS instrument. The IMS apparatus was built at Washington State University by Hill et al. ${ }^{23,24}$. The instrument comprised a drift tube and an electrospray ionization source. The tube had a desolvation and a drift region operating in positive mode, and separated by a Bradbury-Nielsen-type ion gate. The regions had alternating 2.2"-OD, 2.0"-ID alumina insulating spacers ( $99.6 \% \mathrm{Al}_{2} \mathrm{O}_{3}$, Advalue Tech., Tucson, AZ) and conducting stainless steel rings. A counterbore on the external face of each drift ring supplied a pocket for the neighboring ceramic insulator. The ceramic spacers and steel rings were stacked in a horizontally interlocking design. All rings were kept together inside a 2.5"-OD, 2.3"-ID alumina tube housed in an aluminum heating block. One $\mathrm{M} \Omega$ (drift region) or $0.5 \mathrm{M} \Omega$ (desolvation region) high-temperature resistors (Caddock Electronics Inc., $\pm 1 \%$ ) connected the steel rings in series. A $200-500 \mathrm{~V} \mathrm{~cm}^{-1}$ electric field was created throughout the drift tube when a high electrical potential was applied to the first ring. ${ }^{25}$ A countercurrent of preheated $\mathrm{N}_{2}$ buffer gas was introduced at the end of the drift tube at a flow rate of $0.93 \mathrm{~L} \mathrm{~min}^{-1}$ through a stainless-steel tube to help desolvate ions. The buffer gas was passed through a 2 meter stainless-steel tube coiled inside a heated aluminum block for heating (Figure 1). The mobility spectrometer was operated at ambient pressure (690-710 Torr in Pullman, WA). Modified LabView software (National Instruments, Austin, TX) collected the IMS data and controlled the ion gate. IMS gating and data acquisition electronic controls were built at Washington State University (WSU). ${ }^{26}$

Ion gate. The ion gate had eighty parallel wires of $75-\mu \mathrm{m}$ Alloy 46 (California Fine Wire Co., Grove Beach, CA) separated $0.6 \mathrm{~mm}$. When the gate was open, the voltage of all wires was equal to the average of the adjacent drift rings. The gate was closed when $\pm 40 \mathrm{~V}$ were applied to adjacent wires so that a $320 \mathrm{~V} \mathrm{~cm}^{-1}$ orthogonal field stopped positive or negative ions approaching the gate. These voltages neutralized the ions on the negative or positive wires. A narrow pulse of ions entered the drift region to be analyzed when this closure voltage was removed for $0.1 \mathrm{~ms}$.

MS instrument. An ABB Extrel 150-QC (Pittsburgh, PA) quadrupole mass spectrometer $(0-4000 \mathrm{Da})$ was used in these investigations. A Keithley model 427 amplifier (Keithley Instruments, Cleveland, $\mathrm{OH}$ ) was used to amplify the output signal from the electron multiplier detector of the mass spectrometer and to send it to the data acquisition systems. The mass spectrometer was controlled with Merlin software (version 3.0 ABB Extrel, Pittsburgh, PA) which collected the mass spectral data. Igor Pro 5.0.3 (WaveMetrics, Portland, OR) was used to process the spectral data text files.

Modes of operation. There are several possible modes of operation when an ion mobility spectrometer is coupled to a quadrupole mass spectrometer. In radiofrequency-IMS mode (IMS mode), the IMS gate is pulsed, the DC voltages in the mass spectrometer are turned off, and all ions reach the detector; the IMS spectrum of ions of all masses is obtained in this mode. In single ion monitoring-IMS mode (SIM-IMS), the DC and RF voltages in the mass spectrometer are set to allow only ions with a specific mass or a range of masses to reach the detector. SIM-IMS permits the analysis of specific compounds without the interference of others of different masses. In MS mode, all ions enter the mass spectrometer continuously, without pulsing the IMS, and are mass analyzed; in this mode mass spectra are obtained.

Materials and reagents. Ammonia, atenolol, serine, valinol, 2,4-dimethylpyridine (2,4-lutidine), 2,6-di-tert-butyl pyridine (DTBP), tribenzylamine (TBzA), tributylamine (TBtA), and tetramethylammonium (TMA), tetraethylammonium (TEA), tetrapropylammonium (TPA), and tetrabutylammonium (TBA) chlorides (ACS reagent grade, $\geq 98 \%$ purity) were purchased from Sigma Aldrich Chemical Co. (Milwaukee, WI). These reagents were selected as analytes because they supply a series of ions with different molecular weights and steric properties needed to test the effects of size and steric hindrance on the change in mobilities of these molecules with the introduction of ammonia into the buffer gas. Ammonia was used here because in a previous study, water, a molecule of similar size, weight and polarity, was found to interact just slightly with several compounds. ${ }^{21}$ In this study, we investigate if the effects of ammonia in ion mobility are similar to those of water when they are introduced into the buffer gas of a mobility spectrometer to find generalizations on the effects of small modifiers.

Sample preparation and introduction. Analytes were prepared at a concentration of $50 \mu \mathrm{M}$ in ESI solution (47.5\% methanol: $47.5 \%$ water: 5 $\%$ acetic acid). Liquid samples or blank solutions (ESI solution) were infused continuously by electrospray ionization using $250 \mu \mathrm{l}$ syringes (Hamilton, Reno, NV) at a flow rate of $3 \mu 1 \mathrm{~min}^{-1}$ into a $30 \mathrm{~cm}$ long, $100 \mu \mathrm{M}$ ID capillary (Polymicro Technologies, Phoenix, AZ). This capillary was connected to a $50 \mu \mathrm{m}$ ID silica capillary through a stainless steel union (Valco, Houston, TX). The end tip of this capillary was centered at a target screen, placed at the entrance of the mobility spectrometer. The target screen was made out of 2-mm stainless steel mesh and it had a $0.5-\mathrm{cm}$ round hole in the center. A high voltage of $15.6 \mathrm{kV}$ (for a $3.5 \mathrm{kV}$ bias between the capillary tip and the target screen at the first ring) was applied to the stainless steel union to electrospray positive ions. Different syringes and capillaries were used for every compound, whenever it was possible, to prevent cross contamination between the analytes.

Ammonia introduction. Ammonia modifier was introduced into the buffer gas at concentrations of $0.19,0.89,4.4$, and $22 \mathrm{mmol} \mathrm{m}^{-3}$. Ammonia was introduced with gas tight syringes (pumped by a KD Scientific pump, model 210 ) to avoid leaking. The syringes were connected to10-cm-long, $50-\mu \mathrm{m}$ ID silica capillary and this capillary was coupled to a T-junction into the buffer gas line before the buffer gas heater (Figure 1). ${ }^{21}$ The introduction of ammonia before the buffer gas heater provided a longer path to obtain a homogeneous mixture of ammonia with the buffer gas. To help vaporize the modifier, the temperature of the T-junction was increased to approximately $150{ }^{\circ} \mathrm{C}$ using a heating tape (OMEGA Engineering, Stamford, CT). Ammonia flow was countercurrent to the drift of ions to increase the interactions with them. The introduction of ammonia at the end of the drift tube allows a mixture with the buffer gas that is more homogeneous than that obtained when it is introduced with the carrier gas as in experiments when IMS was introduced in the $70^{\prime} \mathrm{s}$.

Identification of compounds. All analytes were detected as protonated molecules, $[\mathrm{M}+\mathrm{H}]^{+}$, or their clusters with ammonia. Analytes were identified by comparison of their $\mathrm{m} / \mathrm{z}$ ratios in mass spectrometry to the molecular weight of their protonated molecules or clusters. Also, reduced mobilities of protonated analytes were compared to those from literature for further identification. Additionally, SIM-IMS was performed to the analyte peaks and their clusters to identify the peaks in the IMS spectrum; when SIM-IMS is applied, only one peak appears in the IMS spectrum.

Calibration. To account for errors in measuring instrumental parameters, Eiceman et al. ${ }^{27}$ recommend correcting reduced mobilities by comparing with standards:

$$
K_{o \text { (unknown })} \cdot t_{d \text { (unknown })}=t_{d \text { (standard) })} \cdot K_{o(\text { standard })}
$$

where $K_{0}$ is the reduced mobility in $\mathrm{cm}^{2} \mathrm{~V}^{-1} \mathrm{~s}^{-1}$ and $t_{\mathrm{d}}$ the drift time in ms. A recently proposed IMS calibration method was used. ${ }^{21}$ This method uses DTBP as the chemical standard to calibrate the instrument by replacing their drift time and mobility value in Equation 1. This method also uses 2,4-lutidine to determine the presence of contamination in the buffer gas.

\section{RESULTS AND DISCUSSIONS}

Table 1 summarizes the percentage reduction in mobilities $\left(\% \mathrm{D} K_{0}\right)$ for the analytes with the introduction of ammonia in the buffer gas. $\% \mathrm{D} K_{0}$ was defined as the percentage difference between $K_{0}$ in $\mathrm{N}_{2}$-only buffer gas and $K_{0}$ when ammonia modifier was introduced into the buffer gas at a given concentration. When ammonia concentration was increased from 0.0 to $22 \mathrm{mmol} \mathrm{m}^{-3}$ at 150 ${ }^{\circ} \mathrm{C}, \% \mathrm{D} K_{0}$ values were: $-1.9 \%$ (reactant ions), $-0.9 \%$ (TBzA), $-1.1 \%$ (TBtA), 
$-4.8 \%$ (serine), $-0.4 \%$ (valinol), $-0.4 \%$ TBA, $-0.5 \%$ (TEA), $-0.3 \%$ (TEA, TMA, and 2,4-lutidine), and $0 \%$ (atenolol and DTBP) (Table 1). In Table 1 , $\% \mathrm{D} K_{0}$ values were not statistically different for TBtA and TBzA. $\% \mathrm{D} K_{0}$ values for TBA, TEA, TMA, TPA, 2,4-lutidine, atenolol, DTBP, and valinol ions, were not statistically different from 0 . Only differences greater than $0.5 \%$ were considered significant; this value was calculated from the maximum relative standard deviation of the drift times, $0.07 \mathrm{~ms}$.

For selected analytes with nitrobenzene (at $\left.0.95 \mathrm{mmol} \mathrm{m}^{-3}\right){ }^{28}$ ethyl lactate (at $1.7 \mathrm{mmol} \mathrm{m}^{-3}$ ), ${ }^{28}$ 2-butanol (at $\left.6.8 \mathrm{mmol} \mathrm{m}^{-3}\right),{ }^{22} \alpha$-trifluoromethyl benzyl alcohol (at $2.3 \mathrm{mmol} \mathrm{m}^{-3}$ ), ${ }^{21}$ and methyl 2-chloropropionate (at $0.93 \mathrm{mmol}$ $\left.\mathrm{m}^{-3}\right)^{21}$ modifiers in the buffer gas, the average $\% \mathrm{D} K$ values were: valinol $(-20 \%), 2,4-$ lutidine $(-13 \%)$, and serine $(-22 \%)$. These $\% \mathrm{D} K_{0}$ values are large compared to those of the same analytes in water or ammonia/water at much larger modifier concentrations (Table 1). This result indicates that to obtain large changes in $K_{0}$ values large modifiers must be used.

Table 1. \% $\mathrm{DK} K_{0}$ values when ammonia and moisture were introduced into the buffer gas. Percent reduction in mobility, $\% \mathrm{D} K_{0}$, for selected compounds at a concentration of $176 \mathrm{mmol} \mathrm{m}^{-3}$ of water in the buffer gas (third column $)^{21}$ and a mixture of water at $106 \mathrm{mmol} \mathrm{m}^{-3}$ and ammonia at $22 \mathrm{mmol} \mathrm{m}^{-3}$ (fourth column). $\% \mathrm{D} K_{0}$ values for water at $7.0 \mathrm{mmol} \mathrm{m}^{-3}$ in the buffer gas were 0.0 indicating a small influence of moisture in ion mobilities. Differences of less than 0.5 units in $\% \mathrm{D} K_{0}$ were not significant and may arise from the standard deviation of the drift time measurements in this work $(0.07 \mathrm{~ms})$; for the same reason, $\% \mathrm{D} K_{0}$ values of $-0.5 \%$ or less were considered zero.

\begin{tabular}{|c|c|c|c|}
\hline Compound & $\begin{array}{c}\text { Molecular weight, } \\
\text { amu }\end{array}$ & Water $^{21}$ & $\begin{array}{c}\text { Ammonia/ } \\
\text { water }\end{array}$ \\
\hline Reactant ions & $\begin{array}{c}19,37,55,73, \\
91 \ldots\end{array}$ & -1.1 & -1.9 \\
\hline $2,4-$ lutidine & 107.1 & -1.2 & -0.3 \\
\hline DTBP & 191.3 & -0.6 & 0 \\
\hline TBA ions & 242.5 & 0 & -0.4 \\
\hline TEA ions & 130.3 & -0.8 & -0.5 \\
\hline TMA ions & 74.2 & -1.5 & -0.3 \\
\hline TPA ions & 186.4 & -0.6 & -0.2 \\
\hline TBzA & 287.4 & 0 & -0.9 \\
\hline Serine & 105.1 & -4.7 & -4.8 \\
\hline Valinol & 103.2 & -1.1 & -0.4 \\
\hline Atenolol & 266 & - & 0 \\
\hline
\end{tabular}

\section{Ammonia and the reactant ions}

The ion mobility spectrum of the electrosprayed solvent is shown in Figure 2 a without introducing ammonia in the buffer gas. IMS spectra were obtained by pulsing the ion gate and setting the mass spectrometer to let all ions pass (radiofrequency-IMS mode). In this spectrum, the main reactant ion peak was observed at a drift time of $13.81 \mathrm{~ms}$ which corresponded to a reduced mobility value of $2.50 \mathrm{~cm}^{2} \mathrm{~V}^{-1} \mathrm{~s}^{-1}$. When the ion gate was held open to obtain mass spectra (MS mode), the main ions peaks were $\left(\mathrm{H}_{2} \mathrm{O}\right) \mathrm{H}^{+}$at $\mathrm{m} / \mathrm{z} 19,37,55$, 73 , and 91 as shown in Figure $2 b$; these peaks might have small contributions of ammonia ions, $\left(\mathrm{NH}_{3}\right)_{\mathrm{n}} \mathrm{H}^{+}$, at $\mathrm{m} / \mathrm{z} 18,35$ etc. The MS spectrum shows that the instrument was clean because no significant peaks appeared above $91 \mathrm{amu}$; it was important to control contamination because contaminants cluster to analytes ions and change their mobilities. ${ }^{21}$ These water clusters combined into one mobility peak in the IMS spectrum at $13.81 \mathrm{~ms}$ due to the equilibria $\left(\mathrm{H}_{2} \mathrm{O}\right)_{1} \mathrm{H}^{+} \leftrightarrow\left(\mathrm{H}_{2} \mathrm{O}\right) \mathrm{H}^{+}+\mathrm{mH}_{2} \mathrm{O}$.

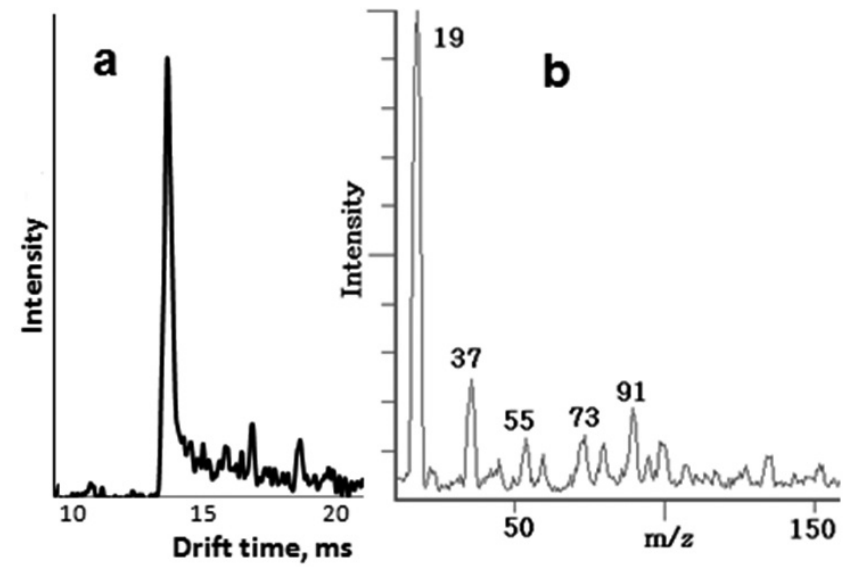

Figure 2. IMS (a) and MS spectra (b) of the ESI solvent in pure nitrogen. The reactant ion peak, $\left(\mathrm{H}_{2} \mathrm{O}\right)_{n} \mathrm{H}^{+}$, showed at $13.81 \mathrm{~ms}\left(2.50 \mathrm{~cm}^{2} \mathrm{~V}^{-1} \mathrm{~s}^{-1}\right)$ in (a); the MS spectrum shows that the instrument was clean

Figures $3 \mathrm{a}$ and $3 \mathrm{~b}$ show the spectra of the reactant ions when $22 \mathrm{mmol} \mathrm{m}^{-3}$ of ammonia was added to the buffer gas; even at the maximum concentration of ammonia used, predominant reactant ions were water clusters at $37,55,73,91$, and $109 \mathrm{amu}$ due to the high concentration of water in the mixture introduced in the buffer gas and the presence of water cluster ions from the ESI solution; however, these peaks might have contributions of ammonia clusters at 35, 52, 69 , and $86 \mathrm{amu}$; water concentration was higher because the modifier was $29 \%$ $\mathrm{NH}_{3}$ in water; water concentrations of $0.90,4.2,21$, and $106 \mathrm{mmol} \mathrm{m}^{-3}$ were concomitant to ammonia concentrations of $0.19,0.89,4.4$, and $22 \mathrm{mmol} \mathrm{m}^{-3}$, respectively; in the IMS spectra in Figure 3a, the major reactant ion occurred at a drift time of $14.08 \mathrm{~ms}$ which corresponded to cluster ions of water and ammonia, with a reduced mobility of $2.45 \mathrm{~cm}^{2} \mathrm{~V}^{-1} \mathrm{~s}^{-1},\left(\mathrm{H}_{2} \mathrm{O}\right)_{\mathrm{n}} \cdot\left(\mathrm{NH}_{3}\right)_{\mathrm{m}} \mathrm{H}^{+}$.

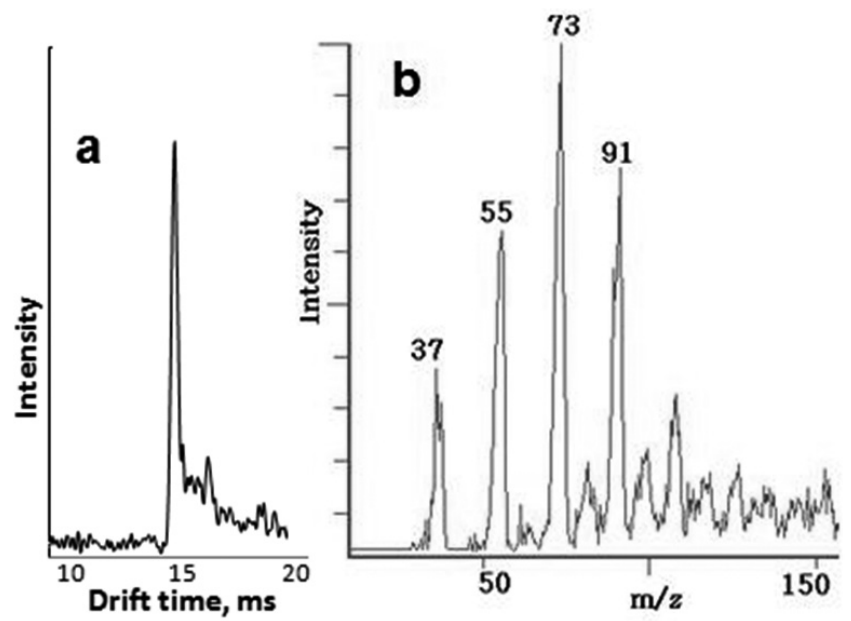

Figure 3. IMS (a) and MS spectra (b) of the ESI solvent (reactant ions) when $22 \mathrm{mmol} \mathrm{m}^{-3}$ of ammonia was added to the buffer gas. The reactant ion peak, $\left(\mathrm{H}_{2} \mathrm{O}\right) \mathrm{H}^{+}$, appeared at $14.08 \mathrm{~ms}$ in (a). The IMS peaks broadened and their mobilities decreased (from 2.50 in Figure 2 to $2.45 \mathrm{~cm}^{2} \mathrm{~V}^{-1} \mathrm{~s}^{-1}$ ) due to interactions with the modifier mixture of ammonia and water.

\section{Drift region equilibria}

The ion mobility peak of serine was observed at $18.47 \mathrm{~ms}$ when a 50 $\mu \mathrm{M}$ solution of the amino acid was electrosprayed into the IMS-MS, with no modifier introduced into the buffer gas (Figure 4a). When ammonia was added to the buffer gas at concentrations of 0.19 and $0.89, \mathrm{mmol} \mathrm{m}^{-3}$ (with concomitant water concentrations of 0.90 and $4.2 \mathrm{mmol} \mathrm{m}^{-3}$ ) the mobility of serine ions decreased from 1.856 , to 1.782 , and $1.760 \mathrm{~cm}^{2} \mathrm{~V}^{-1} \mathrm{~s}^{-1}$, respectively (Figures $4 \mathrm{a}-4 \mathrm{c}$ ). Figure $4 \mathrm{~d}$ is the mass spectrum of serine at $0.89 \mathrm{mmol} \mathrm{m}^{-3}$ of ammonia showing the formation of clusters of ammonia with serine. Ion peaks at $\mathrm{m} / \mathrm{z}$ values of 123.1 and 140.2 were observed which corresponded to the ion 
clusters of $\operatorname{Ser}\left(\mathrm{NH}_{3}\right) \mathrm{H}^{+}$and $\operatorname{Ser}\left(\mathrm{NH}_{3}\right)_{2} \mathrm{H}^{+}$. It is noteworthy that ammonia was more efficient than water in clustering to serine, contrary to what happened when clustering to reactant ions (Figure 2). Further investigation is needed to explain this finding.
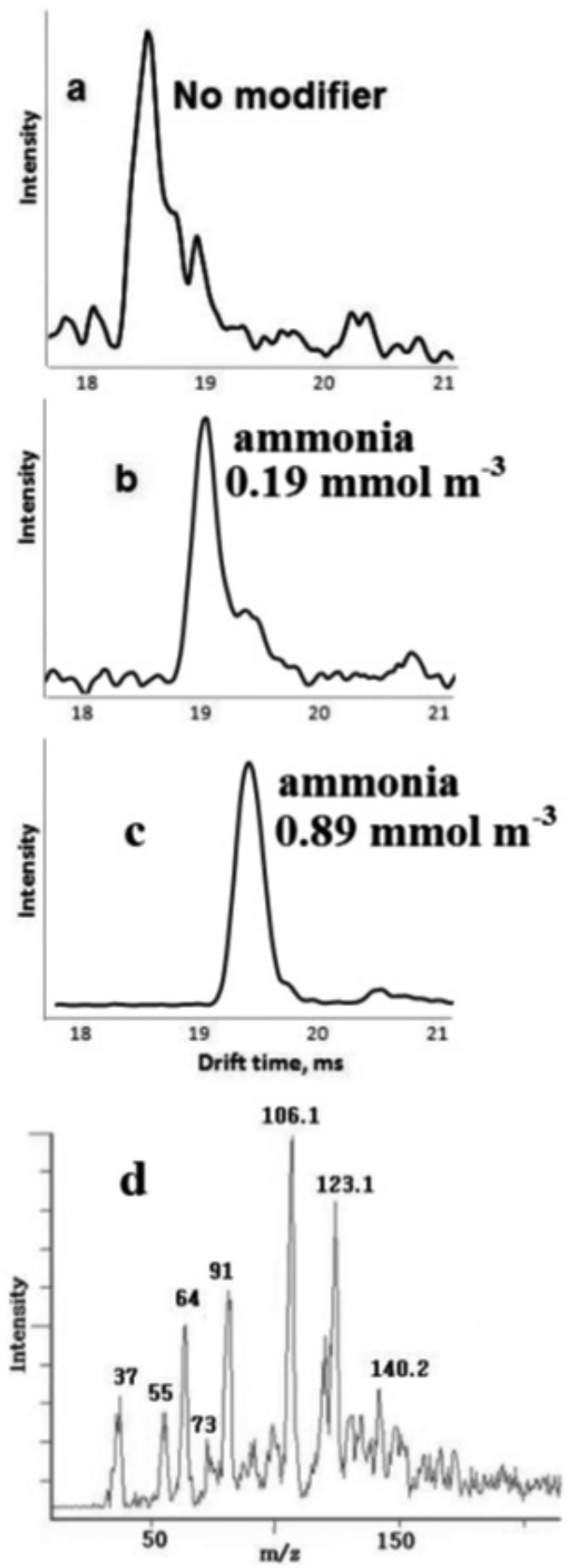

Figure 4. IMS (a-c) and MS spectra (d) of a 50- $\mu \mathrm{M}$ serine solution when $0.89 \mathrm{mmol} \mathrm{m}^{-3}$ of ammonia were added to the buffer gas. The serine ion peaks, $(\mathrm{Ser}) \mathrm{H}^{+}$appeared at $18.46,19.21$ and $19.44 \mathrm{~ms}$ in (a-c) when $0.0,0.19$ and 0.89 $\mathrm{mmol} \mathrm{m} \mathrm{m}^{-3}$ of ammonia were added to the buffer, respectively, which indicated the formation of clusters of serine. The IMS peaks broadened and their mobilities decreased due to interactions with ammonia modifier. The peaks at $\mathrm{m} / \mathrm{z} 106.1,123.1$ and 140.2 are $[\mathrm{Ser} . \mathrm{H}]^{+}$, $\left[\mathrm{Ser} \cdot \mathrm{NH}_{4}\right]^{+}$, and $\left[\mathrm{Ser} \cdot \mathrm{NH}_{3} \cdot \mathrm{NH}_{4}\right]^{+}$. These ions appeared as a single peak in the IMS spectrum which demonstrates that the peaks shown in the mass spectrum (d) were serine-ammonia clusters.
Even if the mass spectra showed two ion clusters and the protonated molecular ion, the ion mobility spectrum contained a single peak for serine. One single peak means that clustering-declustering reactions reached equilibrium in the buffer gas at rates rapid enough to yield only one ion mobility peak with a weighted average of the mobilities of the individual ions; analyte ions traveled across the drift tube rapidly interconverting into the analyte-modifier clusters $\operatorname{Ser}\left(\mathrm{NH}_{3}\right) \mathrm{H}^{+}$and $\mathrm{Ser}\left(\mathrm{NH}_{3}\right)_{2} \mathrm{H}^{+}$, back and forth. Therefore, the following equilibria may have occurred in the drift region between the protonated molecules of serine, ammonia, water, and serine-ammonia-water clusters (only ammonia molecules are included):

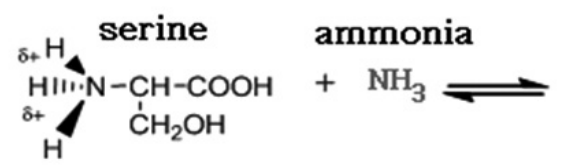<smiles>CCN(C(C)N)[C@@H](C)C#N</smiles>

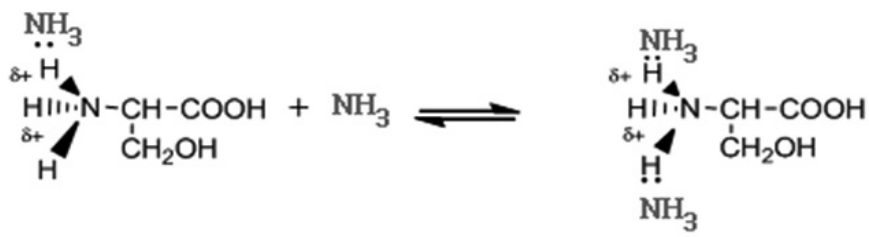

This clustering with ammonia occurred due to the formation of hydrogen bonds between the electronegative nitrogen atom in ammonia and the partially positive charge on the amine hydrogen atoms of serine; clustering with water occurs through the formation of a hydrogen bond with the oxygen atom in water; clustering with ammonia and water stabilized the positive charge by sharing it with the nitrogen atom. As a result of these equilibria, the ion mobility of serine increased with increasing concentrations of ammonia in the buffer gas due to the increasing size of the cluster. The intensity of every ion species in the mass spectrometer was an indication of the relative concentration of the individual ion species that produced the ion mobility peak, assuming that the clusters did not form or decompose at the atmospheric/vacuum interface. At $0.89 \mathrm{mmol} \mathrm{m}^{-3}$, the intensity of the peaks decreased in the order: $(\mathrm{Ser}) \mathrm{H}^{+}$, Ser $\left(\mathrm{NH}_{3}\right) \mathrm{H}^{+}, \operatorname{Ser}\left(\mathrm{NH}_{3}\right)_{2} \mathrm{H}^{+}$indicating a similar decrease in these cluster ion concentrations in the buffer gas; a concentration of $(\mathrm{Ser}) \mathrm{H}^{+}$larger than those of the clusters together with the absence of clusters with more than two ammonia molecules indicates that the buffer gas was not saturated with ammonia or that ammonia did not effectively clustered to serine. The clusters formed in the electrospray ion source, and they were in equilibria with ammonia and water molecules while traveling the drift tube because serine's drift time increased as ammonia concentration increased, and the IMS peaks were well defined.

The maximum number of ammonia molecules clustering with serine was two; this number is smaller than the eleven water molecules that attached to a similar ion, valinol, in a previous experiment maybe because the concentration of water was approximately 40 times larger before ${ }^{21}$ and water occupies part of the available places for attachment. In the experiments with water, \% $\mathrm{D} K$ values at $7.0 \mathrm{mmol} \mathrm{m}^{-3}$ of water in the buffer gas were 0.0 indicating a small influence of moisture in ion mobilities and that the ion mobility reductions observed when ammonia was introduced into the buffer might be especially due to ammonia clustering. This is not contradictory with water clusters present in figures 2-4; because ammonia is a stronger base than water, ammonia clusters with serine better than water even if water was present at high concentrations as is demonstrated by the water clusters observed in figures 2-4.

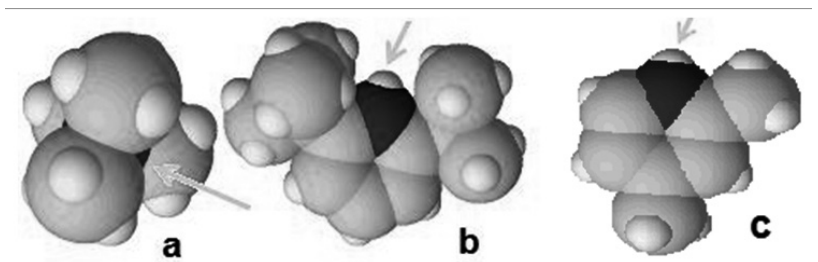

Figure 5. 3D models of (a) TMA, (b) DTBP, and (c) 2,4-lutidine. The arrows signal the positive charge, sterically hindered by the alkyl substituents. The models were generated using the program Chem3D Pro 11.0. Hydrogen: yellow; Carbon: light blue; Nitrogen: dark blue. 


\section{Effects of ion structure on clustering}

$\% \mathrm{D} K_{0}$ values appeared to depend on the size of the substituents on the ion charge. $\% \mathrm{D} K_{0}$ values were small or negligible for tetraalkylammonium, 2,4-lutidine, and DTBP ions which can be explained by steric hindrance on the charge; tetraalkylammonium ions have four bulky alkyl substituents that hinder the attachment of ammonia molecules to the positive nitrogen as has been demonstrated before; ;1,22 the 3D models of TMA, DTBP, and 2,4-lutidine illustrate the steric hindrance in these ions (Figure 5). Figure 6a shows only a single peak for every tetraalkylammonium ion in the IMS spectrum of a mixture of these compounds when $22 \mathrm{mmol} \mathrm{m}^{-3}$ of ammonia were introduced into the buffer gas and clusters with ammonia or water were absent; also, the mass spectrum of tetraalkylammonium ions exhibits only single peaks for these compounds up to $22 \mathrm{mmol} \mathrm{m}^{-3}$ of ammonia in the buffer gas at $150{ }^{\circ} \mathrm{C}$ (Figure $6 \mathrm{~b}$ ) indicating the absence of ammonia or water clusters. Tetraalkylammonium ions appeared at $15.99 \mathrm{~ms}$ (TMA), $19.54 \mathrm{~ms}$ (TEA), $23.97 \mathrm{~ms}$ (TPA) and $28.35 \mathrm{~ms}$ (TBA) in the IMS spectrum and at $\mathrm{m} / \mathrm{z} 75.2$ (TMA), 131.2 (TEA), 186.4 (TPA) and 243.5 (TBA) in the mass spectrum. In DTBP, the hindrance was produced by the two tert-butyl groups and in 2,4-lutidine by the two methyl groups; in both compounds the charge is on a bulky aromatic ring and surrounded by alkyl groups (Figure 5).
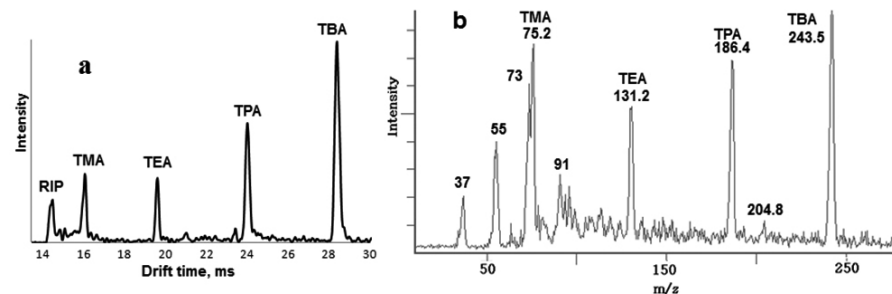

Figure 6. IMS (a) and MS spectra (b) of non-clustering compounds. $50-\mu \mathrm{M}$ solutions of tetraalkylammonium ions, when $22 \mathrm{mmol} \mathrm{m}^{-3}$ of ammonia were added to the buffer gas. Tetraalkylammonium ions have four bulky alkyl substituents that hinder clustering and only a single peak for every ion indicating the absence of ammonia clusters; tetraalkylammonium ions appeared at 15.99 (TMA), 19.54 (TEA), 23.97 (TPA).

Although, size is proportional to mobility, atenolol $\left(266.3 \mathrm{~g} \mathrm{~mol}^{-1}\right)$ was unaffected by ammonia in the buffer gas while the ion mobility of another amine of similar weight, tribenzylamine $\left(287.4 \mathrm{~g} \mathrm{~mol}^{-1}\right)$, decreased; this was because the size of atenolol is much smaller due to the formation of an intramolecular bridge that reduce atenolol size, ${ }^{28}$ this bridge also delocalizes the positive charge which decreases clustering and increase ion mobility.

In general, the changes in mobility with the introduction of modifier into the buffer gas were selective and depended on the analyte structure. $\% \mathrm{D} K_{0}$ values decreased with molecular weight of the analytes; this trend may be due to the small effect on ion size when a molecule of ammonia clusters to large molecules. The selectivity in the reductions in ion mobilities might be applied to the separation of ions, such as valinol and serine; these ions overlap in the IMS spectra in $\mathrm{N}_{2}$-only buffer gas but they reach a separation of approximately 0.1 units of $\% \mathrm{DK}_{0}$ (or one $\mathrm{ms}$ ) when ammonia is introduced in the buffer gas at a concentration of $0.89 \mathrm{mmol} \mathrm{m}^{-3}$ enough to separate them with the resolution of the instrument (Figure 7).

\section{Modifier Saturation}

The sites on an ion to attach ammonia molecules are limited. A decrease in ion mobility change as a function of modifier concentration indicates that the positive charge of analytes is becoming saturated with ligands. ${ }^{22}$ Figure 7 shows a flattening of mobility values at $4.4 \mathrm{mmol} \mathrm{m}^{-3}$ of ammonia in the buffer gas for reactant ion peaks and those analytes that were affected by ammonia introduction such as serine; this flattening indicated saturation with ligands of the hydrogen atoms on the positive charge of the analyte, available for binding with modifier molecules ${ }^{29}$ this saturation, due to high concentrations of ammonia in the buffer gas, would decrease the binding of additional modifier molecules of ammonia to the analytes, and a smaller decrease in mobility would be obtained with increasing concentrations of ammonia modifier. Overloading with ammonia was evident in the presence of clusters of serine with one and two ammonia molecules (Figure 4b).

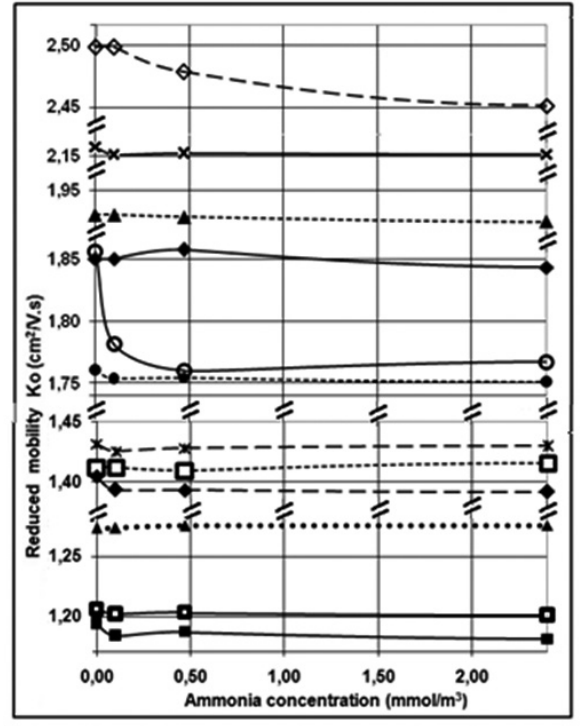

Figure 7. Effect of ammonia concentration in the buffer gas in ion mobility.

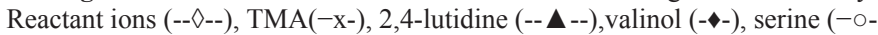
), TEA (--•--), TPA (--*--), DTBP (--口--), tBzA (----), atenolol (.. $\mathbf{\Delta} .$.$) , tBtA$ $(-\square-)$, TBA (--); the mobility of analytes decreased due to the formation of analyte-ammonia-water clusters as ammonia and water concentration increased in the buffer gas. Serine and the reactant ions showed large mobility changes.

\section{CONCLUSIONS}

The aim of this research was to study the addition of buffer gas modifiers in IMS to determine the capabilities of ammonia in generating selective ion separations and to compare the changes in ion mobilities using ammonia with those of water when introduced into the buffer gas. The ion mobilities of several compounds decreased, while other compounds were unaffected, when ammonia was introduced into the buffer gas of an ion mobility spectrometer. The degree of ion mobility reductions for these compounds was also different; the reductions in mobility were produced by the increase in collision cross sections of analytes due to the formation of clusters between the analyte ions and ammonia and water. The structure and size of the analytes determined the extent of clustering in most cases; the mobility of tetraalkylammonium ions and DTBP were less affected by the presence of ammonia modifier because the formation of clusters of these compounds with ammonia was prevented by steric hindrance and also because of their large size; the mobilities of large compounds, such as tribenzylamine and tributylamine were less affected by the attachment of ammonia molecules when compared to smaller compounds such as serine, because the collision cross section of ions of large size is less affected by formation of clusters; on the contrary, the mobilities of small molecules such as serine and the reactant ions were largely affected by clustering with ammonia. These differences in the reductions in ion mobilities might be applied to the separation of compounds which overlap in the IMS spectra in $\mathrm{N}_{2}$-only buffer gas, such as valinol and serine. The change in mobility values as a function of modifier concentration was found to reach a limit at high concentrations of ammonia due to ligand saturation of the hydrogen atoms available for binding on the positive nitrogen of the analytes. Finally, more evidence was obtained that indicate that low molecular weight modifiers produce small changes in the mobilities of ions due to their small effect on the collision cross sections of ions. Some questions remained such as why valinol did not show large changes in ion mobility as those of serine, a compound of similar size and structure.

\section{REFERENCES}

1. M.J. Cohen, F.W. Karasek, J. Chromatogr. Sci. 8, 330, (1970)

2. G.E. Spangler, D.N. Campbell, J.P. Carrico, J. Test Eval. 13, 234, (1985)

3. R.L. Eatherton, M.A. Morrissey, H.H. Hill, Anal. Chem. 60, 2240, (1988)

4. C. Wu, W.F. Siems, H.H. Hill Jr., Anal. Chem. 72, 396, (2000)

5. A.B. Kanu, H.H. Hill Jr., Talanta 73, 692, (2007)

6. A.H. Lawrence, Anal. Chem. 58, 1269, (1986)

7. W.E. Steiner, B.H. Clowers, P.E. Haigh, H.H. Hill Jr., Anal. Chem. $\mathbf{7 5}$, 
$6068,(2003)$

8. D.G. McMinn, J.A. Kinzer, C.B. Shumate, W.F. Siems, H.H. Hill Jr., J. Microcol. Sep. 2, 188, (1990)

9. M.A. Baim, H.H. Hill Jr., Anal. Chem. 54, 38, (1982)

10. R.L. Eatherton, M.A. Morrissey, W.F. Siems, H.H. Hill Jr., J. High Resolut. Chromatogr. Chromatogr. Commun. 9, 154, (1986)

11. C. Wu, W.F. Siems, H.H. Hill, Jr., R.M. Hannan, J. Chrom. A 811, 157, (1998)

12. A.P. Snyder, D.B. Shoff, G.A. Eiceman, D.A. Blyth, J.A. Parsons, Anal. Chem. 63, 526, (1991)

13. S. Myung, J.M. Wiseman, S.J. Valentine, Z. Takats, R.G. Cooks, D.E. Clemmer, J. Phys. Chem. B 110, 5045, (2006)

14. T. Wyttenbach, M.T. Bowers, Top. Curr. Chem. 225, 207, (2003)

15. C. Wu, W.F. Siems, J. Klasmeier, H.H. Hill Jr., Anal. Chem. 72, 391, (2000)

16. P. Dwivedi, C. Wu, S.J. Klopsch, G.J. Puzon, L. Xun, H.H. Hill Jr., Metabolomics 4, 63, (2008)

17. J.A. McLean, B.T. Ruotolo, K.J. Gillig, D.H. Russell, Int. J. Mass Spectrom. 240, 301, (2005)

18. D.L. Albritton, T.M. Miller, D.W. Martin, E.W. McDaniel, Phys. Rev.
171, 94, (1968)

19. H.E. Revercomb, E.A. Mason, Anal. Chem. 47, 970, (1975)

20. P. Dwivedi, C. Wu, L. M. Matz, B.H. Clowers, W.F. Siems, H.H. Hill, Jr. Anal. Chem. 78, 8200, (2006)

21. R. Fernandez- Maestre, C.S. Harden, R.G. Ewing, C.L. Crawford, H.H. Hill Jr., Analyst 135, 1433, (2010)

22. R. Fernandez-Maestre, C. Wu, H.H. Hill, Int. J. Mass Spectrom. 298, 2, (2010)

23. D. Wittmer, Y.H. Chen, B.K. Luckenbill, H.H. Hill, Anal. Chem. 66, 2348 , (1994)

24. C. Wu, H.H. Hill, Jr. A.P. Gamerdinger, Field Anal. Chem. Technol. 2, 155, (1998)

25. H.H. Hill Jr., G.J. Simpson, Field Anal. Chem. Technol. 1, 119, (1997)

26. C. Wu, W.F. Siems, G.R. Asbury, H.H. Hill, Anal. Chem. 70, 4929, (1998)

27. G.A. Eiceman, E.G. Nazarov, J.A. Stone, Anal. Chim. Acta 493, 185, (2003)

28. R. Fernandez-Maestre, C. Wu, H.H. Hill, Rap Commun. Mass Spectrom. 26, 1-13 (2012)

29. H.R. Bollan, J.A. Stone, J.L. Brokenshire, J.E. Rodriguez, G.A. Eiceman, J. Am. Soc. Mass Spectrom. 18, 940, (2007) 